\title{
PARA ONDE FORAM OS BEBÊS? EM BUSCA DE UMA ANTROPOLOGIA DE BEBÊS (E DE SEUS CUIDADORES) 123
}

\section{Alma Gottlieb}

Resumo: Em quase toda a literatura antropológica bebês são frequentemente negligenciados, como se estivessem fora do escopo tanto do conceito de cultura quanto dos métodos da disciplina. Este artigo propõe seis razões para essa exclusão dos bebês da discussão antropológica: as memórias e o status parental do próprio antropólogo, a questão problemática da agência dos bebês e sua suposta dependência de outras pessoas, suas rotinas ligadas às mulheres, sua aparente incapacidade de comunicação, sua propensão inconveniente a vazar através de vários orifícios, e seu aparente baixo grau de racionalidade. A investigação de como os bebês são concebidos fora do mundo ocidental industrializado pode nos levar a percebêlos de uma forma bastante diferente da entendida no Ocidente (inclusive por antropólogos). O confronto entre esses dados comparativos sugere a importância de se considerar os bebês sujeitos relevantes e benéficos para os objetivos da Antropologia.

\section{Palavras-chave: Bebês. Antropologia. Teoria social. África Ocidental.}

1 Esse artigo foi originalmente publicado no periódico Anthropological Quarterly. (2000, July), 73(3), 121-132..

2 Tradução de Carolina Ferreira Fagundes. Revisão técnica de Fernanda Müller e Ana Maria Almeida Carvalho.

3 Artigo baseado em três meses de pesquisa, em 1993; agradeço aos assistentes Beng Véronique A. Akpoueh, Bertin K. Kouakou, Yacoubah K. Bah, Dieudonné K. Kouakou e Augustin K. Yao; aos bebês e seus cuidadores que compartilharam suas opiniões e suas vidas comigo; ao apoio do National Endowment for the Humanities; Wenner-Gren Foundation for Antropological Research; International Programs and Studies (para William and Flora Hewlett Faculty Award) e Center for African Studies, ambos na Universidade de Illinois/Urbana-Champaign. Pesquisas anteriores sobre os Beng $(1979-80,1985)$ foram apoiadas pelo Social Science Research Council, pela American Association of University Women e pela Woodrow Wilson Foundation (Women's Studies Program). Ao John Simon Guggenheim Memorial Foundation e ao Center for Advanced Study, pela licença das aulas para que pudesse escrever este artigo. A Deborah Durham, Philip Graham, Simon Ottenberg e a dois leitores anônimos da revista Anthropological Quartely, pelos comentários sobre versões anteriores; a Judy DeLoache, pelas conversas estimulantes sobre bebês. A meu filho Nathaniel, que me introduziu ao mundo da infância através do seu jeito envolvente; à minha filha Hannah, que continua a inspirar o meu encantamento pela primeira infância e a Philip Graham, por criar e educar junto comigo esses que, espantosamente, não são mais bebês, e por sempre trocar idéias e pensamentos sobre os Beng. 


\section{Para onde foram todos os bebês?}

Quaisquer que sejam as práticas educativas dos pais em suas casas, a maioria dos antropólogos culturais contemporâneos aparenta não pensar muito, de forma analítica, sobre os bebês. É claro que isso não significa que não gostemos de bebês. Mas, em nossa atuação profissional, temos frequentemente ignorado essas criaturinhas, que parecem não ser uma promessa acadêmica segundo o que temos definido como a imaginação etnográfica. Do ponto de vista teórico, os bebês, para a maioria de nós, são um não-sujeito, ocupando um espaço negativo, quase impenetrável para o olhar antropológico. Além disso, os estudos que os privilegiam têm sido excluídos das principais discussões da Antropologia Cultural. Embora esteja surgindo um novo corpo de estudos interdisciplinares sobre a construção cultural da infância e juventude e suas negociações ativas na vida cultural, os bebês ocupam um espaço marginalizado mesmo nessa literatura, que também está apenas começando a atrair a atenção da Antropologia Cultural, especialmente sob o rótulo de "Psicologia Cultural" ou "etnopediatria" (Small, 1998).

No começo deste século, estudiosos associados à Escola da Cultura e Personalidade, inaugurada por Margaret Mead, voltaram sua atenção para as crianças - embora não necessariamente para os bebês. Nos Estados Unidos, essa perspectiva foi bastante influente durante meio século (Langness, 1975). De certa forma, o trabalho de Beatrice e John Whiting, e daqueles que publicaram em sua série Children of Six Cultures, deram continuidade a essa tradição (Whiting, 1963).

Ainda nesses trabalhos, os bebês receberam menos atenção do que as crianças mais velhas. E os críticos salientam o fato de que esses estudos negligenciaram variações no tempo (mudança histórica) e no espaço (etnia/raça, classe, religião e gênero). Além disso, uma perspectiva freudiana excluía interpretações alternativas que poderiam ser mais apropriadas em determinados contextos culturais. Como a própria Mead (1963) reconheceu anos mais tarde, agora sabemos que hipóteses eurocêntricas subjacentes ao modelo freudiano, em sua insistência cultural cega em relação a alguns fatores (como treino de toalete), são interpretadas de diversas formas em diferentes contextos culturais (Wallace, 1983). Essas limitações continuam presentes em estudos mais recentes de orientação psicanalítica sobre bebês e crianças, embora esses estudos, em geral, apresentem grande riqueza de dados ${ }^{4}$.

4 Ver, por exemplo, Parin, Morgenthaler e Parin-Matthéy (1980). Além da perspectiva de Mead, alguns escritos de antropólogos por volta da metade do século também demonstram interesse pela vida das crianças. Por exemplo, alguns dos últimos ensaios de Fortes (1987) contêm um material um tanto disperso, porém bastante interessante, sobre crianças e religião. Mas, além dessas exceções, e da Escola da Cultura e Personalidade, as crianças, especialmente os bebês, sempre foram abordadas de forma muito discreta pela maior parte da Antropologia Cultural da metade do século. Atualmente, alguns escritos sobre educação das crianças e/ou sobre a maior duração desse ciclo de vida com uma perspectiva não freudiana talvez abordem em um capítulo (ou seção) a questão da socialização dos bebês (por exem- 
Com efeito, a etnografia de bebês ainda está engatinhando. Identifiquei apenas duas etnografias completas sobre bebês de uma única sociedade (Hewlett, 1991; LeVine et al., 1994). Não existe atualmente nenhuma revista de Antropologia sobre a primeira infância, e a primeira revista de Antropologia sobre a infância (fundada no Reino Unido) somente agora está em etapa de planejamento 5 . Um dos raros antropólogos que ministra um curso sobre bebês relatou a frustrante falta de informações no banco de dados do HRAF (Arquivos da Área de Relações Humanas), o que dificultou o trabalho de seus alunos (Peters, 1995). Essa situação contrasta agudamente com o campo vizinho da Psicologia, com sua volumosa produção sobre bebês, incluindo uma revista dedicada à primeira infância e muitas outras que frequentemente veiculam artigos sobre esse assunto ${ }^{6}$.

Entretanto, recentemente houve um pequeno aumento de trabalhos sobre crianças, a partir de uma perspectiva da economia política (ScheperHughes \& Sargent, 1998; Stephens, 1995). Os efeitos da economia mundial são bastante explorados nesses trabalhos para situar a vida das crianças, de forma realista, em um contexto globalizado, incluindo o mundo diário do trabalho (para uma revisão sobre o assunto, ver Nieuwenhuys, 1996). Como o impacto da economia e da cultura global em geral vem sendo documentado em lugares aparentemente remotos (Appadurai, 1996; Comaroff \& Comaroff, 1991, 1997; Dirks, Eley, \& Ortner, 1993; Gupta \& Ferguson,

plo, Morton, 1996). Da mesma forma, alguns trabalhos cujo foco é especificamente os rituais próprios desse ciclo de vida incluem discussões sobre as crianças pequenas e, às vezes, sobre a primeira infância (Lafontaine, 1985; Ottenberg, 1989). Pesquisando um pouco mais, podese encontrar um grande número de etnografias gerais que talvez contenham capítulos ou, mais provavelmente, pequenas seções dedicadas ao período da primeira infância (em geral, associadas às considerações sobre a fase de aquisição de independência locomotora). Mas essas considerações geralmente ocorrem em meio ao desenvolvimento de questões relevantes para uma sociedade específica, ao invés de se constituir em um foco nas crianças em si mesmas (W. James, 1979; Seremetakis, 1991). Por mais instigantes que algumas dessas discussões possam ser, elas, inevitavelmente, não apresentam a profundidade e a riqueza de detalhes que apenas um estudo específico do assunto poderia oferecer. Além dos trabalhos mencionados, tenho observado uma crescente literatura de estudiosos que abordam uma variedade de questões relacionadas à reprodução. Um subgrupo desses estudiosos analisa, de forma sutil, o imaginário cultural do feto e os processos mais gerais envolvidos na procriação (Héritier, 1994, 1996; Jorgensen, 1983; Morgan, 1997); outro grupo importante investiga a variedade de estratégias e decisões reprodutivas disponíveis às mulheres em diferentes contextos culturais (ver Ginsburg \& Rapp, 1991); nos trabalhos mais recentes, incluem-se Davis-Floyd e Sargent (1997), Franklin e Ragoné (1998), Ginsburg e Rapp (1995). Juntos, esses vários estudos falam indiretamente sobre a vida dos bebês e podem ser aproveitados para aprimorar uma Antropologia dos bebês em desenvolvimento.

5 Intitulada Child, Culture and Society, essa nova revista será baseada no Department of Human Sciences/Centre for Child-Focused Anthropological Research, da Universidade de Brunel. Outra revista multidisciplinar de orientação internacional, Childhood (iniciada em 1994), também inclui algumas discussões sobre crianças, mas seu foco está mais voltado para os problemas sociais contemporâneos do que para uma abordagem acadêmica per se.

6 No entanto, os psicólogos especializados em bebês vêm manifestando a tendência de concentrar suas pesquisas em uma pequena gama de aspectos relacionados aos bebês - aqueles que dizem respeito às famílias europeias e americanas de classe média (DeLoache, 1992). Além disso, a grande maioria dos estudos psicológicos é baseada em observações de bebês em laboratórios, e estão muito longe de observá-los em suas vidas diárias (Goldberg, 1977). 
1997a, 1997b; Hannerz, 1996; Piot, 1999), o esforço para incluir as crianças em análises que consideram os fluxos econômicos e culturais mundiais é muito bem-vindo.

Por mais reveladores que sejam, do ponto de vista da Antropologia da primeira infância esses estudos sobre crianças são limitados de duas formas. Do ponto de vista empírico, a maioria deles, mais uma vez, tende a enfocar mais as crianças maiores do que os bebês. Teoricamente, a perspectiva da economia política, por si só, tem seus limites. E, o que é mais perceptível, frequentemente está ausente em trabalhos que abordam o ponto de vista da economia política a percepção da perspectiva nativa sobre as experiências das crianças e como essas se relacionam com outros aspectos culturais do panorama social - incluindo religião e outras estruturas ideológicas. Como em outras etnografias, encontrar o equilíbrio ideal entre o global e o local, o político e o cultural, o social e o individual, vem sendo um desafio para muitos desses estudos.

Recentemente, temos visto alguns exemplos bastante promissores de pesquisadores americanos treinados ou influenciados pela Antropologia e que estão focalizando extensivamente a vida de bebês, de crianças pequenas e de seus pais, alguns deles trabalhando conjuntamente com pesquisadores de áreas correlatas (Harkness \& Super, 1983; Kilbride \& Kilbride, 1990; Lancy, 1996; Levine et al., 1994; Munroe \& Munroe, 1980; Riesman, 1992; Super \& Harkness, 1980, 1986). Um desenvolvimento paralelo também ocorreu na Europa (Bonnet, 1988; Erny, 1988; Lallemand, 1991; Lallemand \& LeMoal, 1981b; Toren, 1988, 1993). Esses autores são notáveis pela extensão com que identificam fatores culturais que afetam o bebê e 0 desenvolvimento das crianças a partir de perspectivas sofisticadas.

A discussão sobre a matriz social da vida das crianças parece estar se desenvolvendo mais rapidamente em outras áreas do que na Antropologia. Desde o estudo inicial de Ariès, a História e a Sociologia, em especial, são os campos mais férteis para o surgimento de discussões sobre as crianças como culturalmente situadas (Davin, 1997; Hunt, 1997; Itoua et al., 1988). De fato, considerando o peso acumulado desse trabalho interdisciplinar, dois autores ultimamente sugeriram que "está emergindo um novo paradigma para o estudo da infância" (James \& Prout, 1990, p. 2). Ainda que esse trabaIho em desenvolvimento tenda a sub-representar as experiências dos bebês em comparação com as das crianças mais velhas, o desenvolvimento acadêmico é notável. Juntos, esses autores da Antropologia e de disciplinas correlatas indicam caminhos encorajadores, para os quais o desenvolvimento da Antropologia da primeira infância pode estar se direcionando7.

7 Embora esteja direcionando o foco para a Antropologia Cultural, assinalo que, dos quatro subcampos da Antropologia, provavelmente a Antropologia Linguística seja o subcampo que mais voltou sua atenção para o mundo das crianças (Heath, 1983; Schieffelin, 1990; Schieffelin \& Ochs, 1986a, 1986b), embora Goodwin (1997) recentemente tenha comentado o quanto ainda precisa ser pesquisado sobre a linguagem das crianças. Também vale assinalar que, no campo relacionado da Antropologia Biológica, há uma correspondente falta de 
Até agora, foram utilizados os termos "bebê" e "primeira infância" de uma forma um tanto indiscriminada, como se fossem por si só evidentes. Se a Antropologia Cultural nos ensinou algo ao longo de todo o século passado, foi o fato de que as expressões aparentemente mais transparentes com frequência se mostram surpreendentemente não comparáveis. Isso é válido para categorias tão diversas quanto as que se referem ao tempo, ao espaço, às relações familiares, à religião, à estrutura política, aos sistemas de numeração, entre outras. Desse modo, o que se considera como "semana" em sociedades africanas tradicionais pode variar de três a oito dias (Zaslavsky, 1973). Ou também o que parece "política" em um lugar por exemplo, nas nações ocidentais - se configura suspeitamente como "religião" em outros - como ocorre em muitos lugares da África (Arens \& Karp, 1989). Até mesmo as operações matemáticas são alvo de redefinições surpreendentes - o que parece ser adição para um ocidental pode ser interpretado como subtração (e vice-versa) entre alguns grupos nativos do Brasil (Ferreira, 1997). Um século de revelações desestabilizadoras como essas deve ter nos alertado para a natureza não transparente de muitos conceitos supostamente transparentes. Por que então as categorias "bebê" e"primeira infância" deveriam ser menos problemáticas?

Os psicólogos do desenvolvimento frequentemente definem a "primeira infância" estritamente como o período que engloba desde o nascimento até o começo da fase de independência locomotora que, de acordo com suas definições, normativamente começa a partir dos dois anos de idade (por motivo de conveniência, exceto nos casos assinalados, é com esse sentido que o termo é usado nesse artigo). A transição do final do segundo ano para o começo do terceiro é vista pelos psicólogos como o marco de referência para crianças pequenas (saudáveis e com desenvolvimento normal) começarem a compreender e responder à comunicação linguística e a andar de modo eficiente, sem quedas constantes.

Esse "passo a frente", no entanto, não é uma certeza biológica, mas uma convenção cultural pressuposta no calendário ocidental. A definição de dois anos para o fim da primeira infância também é pressuposta na hipótese cultural de que os estágios da vida devem ser definidos em relação a espaços de tempo específicos, ao invés de mudanças de atividades (Evans-Pritchard, 1940). Entre crianças pequenas, há uma ampla variação das habilidades verbais e motoras aos dois anos de idade (Cole, 1983). $O$ entendimento nativo dos estágios da vida será necessariamente diferente em sociedades que não estabelecem pontos fixos no calendário como determinantes.

abordagens acadêmicas sobre os bebês e a anatomia das crianças (exceto relacionadas ao período fetal). Um artigo breve do biólogo evolucionista Stephen Jay Gould (1996) é uma das obras mais recentes que consideram tais questões (Stephen Leigh, comunicação pessoal). Alguns arqueólogos também vêm contribuindo com um volume significativo de estudos acadêmicos com foco em bebês e crianças pequenas tanto recentemente quanto em um passado mais distante. 
De fato, ao invés de identificar um período de tempo absoluto para a primeira infância, muitos povos não ocidentais possuem uma abordagem mais contextual, que depende da aquisição de uma habilidade desenvolvimental específica (tal como andar ou falar) considerada como um marco, não importando quando ela tenha sido adquirida por uma determinada criança. Por exemplo, os Lahu do sudoeste da China afirmam que as crianças permanecem no estágio "vermelho e nu" (o qual talvez possamos traduzir por "primeira infância") até que consigam caminhar com segurança e, mais importante do que isso, falar com certo grau de expressão. Mas os Lahu reconhecem que a aquisição dessas habilidades pode ocorrer em tempos diferentes para cada criança, e resistem em especificar uma duração de tempo para o estágio "vermelho e nu" (Du, 2002).

Mesmo quando uma idade absoluta é aceita como parâmetro para o fim da primeira infância, essa idade pode variar histórica e culturalmente. Como exemplo, os puritanos da Nova Inglaterra acreditavam que a primeira infância terminava ao final do primeiro ano (ao invés dos dois anos da ciência ocidental contemporânea), quando afirmavam que o demônio começava a exercer controle. Para combater essa influência, os líderes puritanos faziam com que os pais introduzissem uma disciplina rígida imediatamente após o aniversário de um ano (Reese, 2000). Já os Ifaluk, da Micronésia, prolongam a primeira infância, utilizando a demonstração que os psicólogos do desenvolvimento chamariam de senso moral como ponto de referência para o término desse estágio. Os Ifaluf mantêm a idéia de que as crianças pequenas permanecem irracionais até os cinco ou seis anos de idade, adquirindo inteligência lentamente entre dois e três anos, mas não conseguem assimilá-la de forma completa até atingirem o estágio correspondente à infância (sari) - a partir de cinco ou seis anos de idade (Le, 2000; Lutz, 1988).

Se o final da primeira infância é variável de acordo com a cultura, o mesmo vale para o seu começo. Embora o nascimento pareça ser a inauguração mais óbvia desse período, Geertz (1983) nos ensinou que, às vezes, o significado que é considerado senso comum para alguns, para outros pode ser tudo menos isso. Dessa forma, alguns povos determinam que a primeira infância começa já no útero, enquanto outros a adiam para o momento posterior ao nascimento. Contemporaneamente, nos Estados Unidos, esse é um tema que envolve bastante debate entre ativistas "pró-aborto", basicamente não-religiosos, e "pró-vida", basicamente religiosos (Morgan, 1996).

Se o modelo ocidental dominante não-religioso sugere que a primeira infância começa imediatamente após o nascimento, em outros lugares talvez esse não seja o caso. Alguns povos muçulmanos mantêm um ritual de nomeação depois do sexto dia e, antes do ritual, o recém-nascido não é, de modo algum, um bebê, já que ainda não adquiriu nenhum senso de identidade (D'Alisera, 1998; Johnson, 2000). Outros grupos chegam a adiar ainda mais o início desse estágio. Por exemplo, os aborígines Murngin de Arnhem Land chamam os recém-nascidos por um termo equivalente a "feto". So- 
mente quando o recém-nascido começa a sorrir - aproximadamente entre três e seis semanas - é chamado de "criança",e esse estágio dura até que ela tenha entre nove e doze anos de idade (Hamilton, 1981). Em outros lugares, pode haver uma concepção mais indeterminada mesmo sobre o começo da identidade pessoal. Entre os Wari', do Brasil, por exemplo,"a identidade é adquirida gradualmente, e pode ainda ser perdida ou atenuada sob determinadas circunstâncias..., embora, de alguma forma, inicie após a primeira amamentação" (Conklin \& Morgan, 1996, p. 658, 678).

O estágio da primeira infância estaria presente em todas as sociedades contemporâneas ou uma dada sociedade talvez possa desistir de considerar os primeiros meses ou anos com uma concepção especial e/ou consideração ritual (como aparenta ocorrer em Arnhem Land)? A relativa falta de conhecimento sobre a vida, os hábitos e concepções dos bebês em diferentes culturas torna difícil responder a essa e outras questões relacionadas com exatidão. Enquanto vários antropólogos já mencionaram os bebês mais ou menos de passagem, poucos os consideraram de forma séria como sujeitos próprios da pesquisa antropológica.

Por que até hoje não existe uma Antropologia sistemática da primeira infância?

Por que os bebês se foram?

Nessa seção apresentarei seis razões que explicam o espaço relativamente pequeno que os bebês ocupam não somente no mundo empírico, mas também no corpus antropológico.

\section{1) Lembrar a infância, imaginar a parentalidade?}

A experiência pessoal pode interferir em dois níveis com uma lacuna perceptível na discussão antropológica dos bebês. Em primeiro lugar, embora todos os adultos já tenham sido bebês, poucos - se é que existem - lembram dessa experiência. Essa falta de memória (salvo o que os pais e outras pessoas possam implantar depois desse período) pode nos desencorajar a considerar um aspecto da experiência humana que parece muito remoto da nossa perspectiva individual ${ }^{8}$.

Além disso, muitos antropólogos culturais são relativamente jovens - a maioria está perto dos trinta anos -, estão começando a trabalhar na área e (ainda) não têm filhos. Desse modo, podem desconhecer os desafios (emocionais, médicos, pragmáticos e teóricos) que os bebês impõem. Essa ignorância talvez possa tornar improvável a visualização de um estudo antropológico sobre o assunto. Mais tarde, aqueles que vierem a se tornar pais (sobrecarregados de trabalho), talvez não tenham mais o luxo de poder conduzir trabalhos de campo (sobre bebês ou qualquer outro tema). 
A parentalidade seria um pré-requisito para se desenvolver um estudo sobre os bebês? Na verdade, uma das marcas clássicas da Antropologia Cultural é estudar o "Outro". Certamente é difícil imaginar um outro mais diferente para os adultos do que os bebês, qualquer que seja o contexto cultural de ambos. Assim, em teoria, a parentalidade não deveria ser um pré-requisito para o estudo das crianças. Na verdade, o status de outsider pode ser uma vantagem, sob o ponto de vista analítico, para os antropólogos que ainda não tiveram filhos ao investigarem a vida das crianças. Por enquanto, esse lado analítico ainda não foi aprimorado 9 . Ironicamente, mesmo os pais - sem falar dos que não o são - raramente assumiram o desafio de tal empreitada antropológica sobre o ciclo de vida desses "Outros", apesar da nossa missão disciplinar de encorajar esse caminho intelectual. Mas por que é assim?

\section{2) A "agência" perdida dos bebês?}

Quanto menor a criança, mais dependente ela é de outros para o seu suporte básico biológico: para os padrões antropológicos, os bebês aparentam ser desinteressantes. Eles parecem precisar tanto da misericórdia dos outros que não existe nem um mínimo grau daquela relação de oferta e demanda entre dois indivíduos, ou entre um individuo e a sociedade em geral, que torna a reflexão acadêmica tão interessante. Outro fato relacionado a essa questão é o de que os bebês, na maioria das sociedades - se não em todas -, são classificados como menores. Incapazes de testemunhar em tribunal, eles não produzem nenhum efeito legal sobre outros. Dada a base legalista da herança da maior parte das nossas disciplinas (britânicas/ funcionalistas) - especialmente na África -, o legado de tal posicionamento jurídico inconsequente dos bebês parece pertinente mesmo hoje em dia, e talvez, inconscientemente, sirva como mais um fator responsável por sua invisibilidade etnográfica. Em geral, a opinião dos bebês parece ser irrelevante na tomada de decisões que envolvam outras pessoas. Como informantes, bebês aparentemente não contribuem com um material muito promissor.

Entretanto, como sabem muitos pais recentes, a passividade está muito longe de ser uma descrição completa da vida de um recém-nascido. Desde o começo, os bebês demandam serem levados em conta, embora adultos não interpretem essa demanda de maneira acurada. Os antropólogos de bebês são como os pais, buscando aprender uma nova linguagem, que não só não possui um dicionário pronto ou uma gramática publicados como, sem dúvida, apresenta regras ocultas, isso se puderem ser descobertas - ou, como diriam alguns psicólogos do desenvolvimento, ser mutuamente criadas (Lewis \& Rosenblum, 1974).

Para duas notáveis exceções ver Briggs (1998) e Ottenberg (1989). 
Além disso, membros de cada sociedade podem ter suas próprias idéias sobre o assunto e desejar se diferenciar do modelo de passividade dos bebês assinalado acima. De acordo com alguns pontos de vista, eles podem ser considerados determinantes da vida das pessoas ao seu redor. Ao longo do trabalho de campo na Costa do Marfim, quanto mais eu investigava a vida dos Beng adultos e de crianças mais velhas envolvidas com o cuidado dos bebês, mais descobria que suas decisões diárias eram definidas em função da rotina dos bebês (Weisner \& Gallimore, 1977). Os Beng adultos afirmavam que os bebês são reencarnações de seus ancestrais e, dessa forma, nos primeiros anos de suas vidas, lembram com saudade de suas existências prévias (Gottlieb, 1998, 2000,2004). O dever maior dos pais Beng é o de discernir (por meio de adivinhos) quais os desejos que os bebês supostamente trouxeram de suas encarnações anteriores, para então atendê-los. Nessa perspectiva, os bebês Beng estão longe de ser criaturas indefesas sem opinião ou impacto sobre o mundo. Para os Beng, assim como para muitas sociedades não ocidentais, a suposta dependência total dos bebês, da forma como é amplamente pressuposta por antropólogos ocidentais, não existe - e, portanto, desafia a nossa ideologia implícita de que bebês são criaturas passivas, o que impediu a possibilidade de privilegiarmos os bebês como sujeitos legítimos, e muito menos como produtores ativos de cultura.

\section{3) Bebês e mulheres}

Os bebês, na maioria das sociedades, passam a maior parte do seu tempo junto às mulheres - em geral, embora não necessariamente, suas mães ${ }^{10}$ - e até duas décadas atrás, essas eram negligenciadas como sujeitos sociais por muitos antropólogos. Mesmo as feministas tendiam a privilegiar os estudos mais fáceis - e teoricamente menos perigosos - sobre os domínios "públicos" da vida das mulheres, o que mais se aproximava da vida "pública" dos homens - o envolvimento das mulheres na economia, nas redes sociais e na estrutura política. $O$ trabalho maternal que as mulheres fazem no mundo todo permaneceu por muito tempo nas sombras, relegado à chamada esfera doméstica (Stack \& Burton, 1994). Mesmo quando começamos a prestar mais atenção em suas vidas reprodutivas, os produtos de toda essa reprodução - os próprios bebês - permaneceram esquecidos.

Felizmente, as antropólogas feministas reorientaram as discussões sobre o envolvimento aparentemente privado das mulheres - incluindo a arena definida como doméstica - como algo inteiramente cultural e com um impacto direto nos eventos públicos. No plano teórico, o limite conceitual entre o público e o privado, até então transparente, passou a ser questionado, afrontando a definição de categorias centrais da maior parte

10 Para o caso de pais que tomam conta dos bebês, ver Hewlett (1991). 
da nossa disciplina (Comaroff, 1987; Lugo \& Maurer, 2000). Um confronto teórico desse tipo poderia beneficiar o estudo sobre bebês.

\section{4) Os bebês podem se comunicar?}

Os bebês são - ou pelo menos aparentam ser - incapazes de falar. A maioria de nós valoriza a afirmação de que a linguagem sinaliza a presença da cultura. Já que bebês não podem comunicar seus desejos e pontos de vista de forma que os antropólogos se sintam proficientes para interpretálos, como podemos admitir essas criaturinhas dentro do nosso tão estimado domínio da "cultura"? Mesmo se supusermos que os bebês têm uma vida cultural secreta, como um antropólogo pode começar a entender o mundo desses seres humanos não-linguísticos?

Em primeiro lugar, os diversos sons que os bebês produzem - frequentemente desprezados pelos observadores ocidentais que os consideram somente ruídos sem sentido - podem ser considerados significativos em determinados lugares. Prestar atenção aos sons que eles produzem, se são compreendidos - e como o são - pelas pessoas em sua volta, poderia proporcionar uma pesquisa intelectualmente produtiva.

Além disso, mesmo que os sons dos bebês sejam considerados sem sentido localmente, o obstáculo imposto pela falta de competência verbal para alcançar um senso de Verstehen (compreensão), pode não ser tão difícil quanto aparenta. Os impedimentos para se conseguir comunicação mesmo entre adultos são bem conhecidos atualmente. Registros de trabaIhos de campo já demonstraram amplamente que a total empatia e compreensão de outro ser humano - mesmo de alguém que se situe dentro da própria tradição cultural do observador (independente de como essa seja definida) - é, na melhor das hipóteses, difícil, talvez mesmo impossível de se conseguir. No entanto, a maioria dos antropólogos culturais afirmaria que o esforço para se atingir um nível de empatia e compreensão de um dado grupo de Outros tem um papel central no empreendimento etnográfico. Dessa forma, a maioria de nós parece prosseguir com a esperança de que uma realização parcial desse objetivo bastante elevado e difícil de atingir seja possível. A situação dos bebês talvez não seja muito diferente.

Entretanto, para conseguirmos uma comunicação, é necessário que ajustemos os métodos de campo. Os estudantes de língua vêm sugerindo que o critério clássico para identificar um "texto" - a presença de um sistema de escrita alfabético ou ideográfico - pode ser muito restrito. Outros sistemas de comunicação - vestimentas e adornos, jogos, etiqueta etc. poderiam ser analisados produtivamente como textos semióticos ${ }^{11}$. Desse modo, sugiro que faz sentido considerar a vida dos bebês como textos a serem lidos, embora possivelmente com um novo conjunto de lentes.

11 Para um exemplo clássico, ver Barthes (1972); para uma revisão de orientação teórica das questões envolvidas, ver Hanks (1989). 
Precisaríamos investigar como os adultos de uma dada localidade dizem que seus bebês se comunicam - e com quem. Durante meu trabalho de campo, os adultos Beng relataram-me que, de fato, os bebês desejam se comunicar, mas que os adultos não são iluminados o suficiente para entender suas tentativas. Portanto, pais Beng sentem necessidade de consultar adivinhos, que falam a língua dos bebês através de espíritos intermediários que habitam o mundo espiritual - do qual acreditam que os bebês acabaram de (parcialmente) emergir. Bebês enunciam seus desejos, os quais os adivinhos interpretam para os pais; em contrapartida, os pais são obrigados a satisfazer esses desejos, frequentemente tendo que adorná-los com várias joias (Gottlieb, 1998). Em face dessa ideologia, o meu imperativo metodológico durante o trabalho de campo era consultar os adivinhos e frequentar as séances (sessões) sobre bebês o quanto fosse possível. Privilegiar a comunicação com os espíritos por meio de adivinhos não é uma tarefa para a qual somos normalmente treinados. Entretanto, devemos aos nossos informantes sobre os bebês acompanhá-los para onde quer que as suas tentativas de comunicação culturalmente mediadas nos conduzam independente de serem essas relativas ao mundo espiritual ou a algum outro espaço inesperado, mas culturalmente significativo, incluindo o corpo.

A dominância da comunicação verbal com adultos humanos sobre outras formas de comunicação está começando a ser questionada em alguns trabalhos recentes. Stoller (1997), Farnell (1994) e outros têm nos mostrado a necessidade de buscar dados em outras formas de comunicação sensorial que não a linguagem verbal. As interpretações locais de como os bebês se comunicam talvez nos levem para muito além de nossos modelos verbais. $O$ estudo de bebês nos permitiria considerar seriamente o imperativo teórico, que esses estudos estão exigindo, de somatizar nossos métodos.

\section{5) Corpo de bebês, fluidos de bebês}

A habilidade verbal que falta aos bebês é compensada por suas comunicações somáticas. Os bebês são bagunceiros - quanto menores, mais bagunceiros. Eles passam a maior parte do tempo mais envolvidos em processos corporais do que em atividades intelectuais. A maioria desses processos envolve a expulsão de substâncias que são desvalorizadas na sociedade ocidental (Bakhtin, 1968) - lágrimas, urina, fezes, vômito. Como intelectuais, os antropólogos não são treinados para entender essas exúvias como materiais apropriados à pesquisa acadêmica, apesar do modelo fértil de Mary Douglas (1966) para analisar secreções e "matéria fora do lugar".

Contudo, em alguns lugares, esses processos corporais dos bebês podem ser culturalmente significativos. Entre os Senufo do norte da Costa do Marfim e sul de Burkina Faso, por exemplo, a urina é considerada um presente 
do bebê, um meio de estabelecer um relacionamento com quem quer que o esteja segurando (Lamissa Bangali,comunicação pessoal). Esse modelo de comunicação baseado no corpo desafia os modelos predominantes da sociedade ocidental de estabelecer relacionamentos sociais que privilegiam a troca verbal. Mudar o eixo teórico das cordas vocais para o trato urinário abalaria nosso modelo de comunicação baseado na linguagem e, ao mesmo tempo, poderia violar nossas próprias noções de higiene corporal.

Outro aspecto referente ao corpo dos bebês que pode revelar dados culturalmente ricos é o seu desenvolvimento motor - que há muito tempo é visto pelos psicólogos como invariável em bebês saudáveis. Ao prestar atenção em como os Baganda adultos, de Uganda, fazem os seus bebês de um a três meses de idade sentarem nos seus colos, e apoiam os de três a quatro meses no chão a fim de treiná-los a sentar-se independentemente e sorrir, Kilbride e Kilbride (1975) demonstraram que os bebês Baganda saudáveis conseguem se sentar sozinhos, em geral, aos quatro meses de idade, bem mais cedo do que os bebês europeus e americanos oriundos de famílias de classe média usualmente conseguem fazê-lo. A razão é eminentemente cultural: sentar-se e sorrir permite ao bebê se comunicar com quem está à sua volta, uma vantagem valiosa no reino insistentemente face-a-face dos Baganda. Retomar essa área do desenvolvimento motor, que em grande parte abandonamos para os psicólogos do desenvolvimento como sendo biologicamente determinada, pode trazer surpresas que interessam a ambas as disciplinas, mostrando que esse aspecto do desenvolvimento vem sendo sobredeterminado por uma variedade de forças.

Uma linha de pesquisa igualmente promissora se relaciona com o que bebês fazem muito: dormir. Os antropólogos vêm coletando há algum tempo materiais que indicam que o hábito de dormir com os pais - geralmente, mas nem sempre com a mãe - predomina em bebês e crianças pequenas nas sociedades não industrializadas (Crawford, 1994; Small, 1998). Uma etnografia sobre o sono dos bebês poderia perguntar: os bêbes dormem na vertical ou na horizontal, esticados (como nas pranchas-berço dos americanos nativos) ou enrodilhados (como nas redes da América Central)? Quanto tempo eles dormem em lugares calmos ou barulhentos? Por quanto tempo dormem sem acordar - durante o dia e à noite? E de que forma as ideologias locais relacionadas ao sono dos bebês interagem com as práticas locais? Em outras palavras, qual o sentido cultural de tais padrões? Prestar atenção à formatação cultural de práticas somáticas tais como o sono pode levar a uma adaptação do método de amostragem de tempo, que é bem desenvolvido para o estudo sobre a vida dos adultos (Gross, 1984). As atividades diárias dos bebês poderiam ser comparadas para se obter uma perspectiva tanto da extensão como dos limites de variação de suas experiências.

As respostas para essas questões podem revelar variações significativas, tanto interculturalmente quanto intraculturalmente. Mesmo entre 
bebês da mesma idade podem ocorrer diferenças significativas devido a fatores como estrutura familiar, renda e orientação religiosa. Para os psicólogos, esse tipo de estudo pode demonstrar, em última instância, que os desenvolvimentalistas devem ser cautelosos ao fazer generalizações interculturais sobre desenvolvimento e comportamento de bebês baseadas em estudos limitados culturalmente. Para os antropólogos, tais estudos demonstrariam que os corpos dos bebês são marcos significativos que apontam valores culturais críticos. Em um nível mais teórico, eles ainda reforçariam o argumento a favor da relatividade cultural, mesmo quando se trata do aparentemente impenetrável bastião do desenvolvimento biológico.

\section{6) Bebês são racionais?}

Finalmente, processos corporais foram, por muito tempo, assumidos pelos ocidentais como representantes de nossas mais estreitas ligações com a natureza biológica e, desse modo, mais impenetráveis para a influência cultural do que outros aspectos de nossas vidas. Não é de se admirar que os bebês, com seu grau dominante de envolvimento com o corpo, sejam definidos como pré-culturais, ou o que passei a pensar como uma espécie de "pacote biológico".

Atualmente, entretanto, processos biologicamente influenciados, como sexualidade (Caplan, 1987), gravidez e nascimento (Jordan, 1993), amamentação (Maher, 1992), menstruação (Buckley \& Gottlielb, 1988) e alimentação (Couniham \& Van Esterik, 1997) têm sido identificados como questões apropriadas para o olhar do antropólogo cultural. Realmente, a noção dos sentidos e do corpo em geral como culturalmente construídos é uma proposta séria (Classen, 1992; Lock, 1993; Strathern, 1997). Levando em conta essas mudanças teóricas, é tempo de nossa disciplina considerar seriamente as afirmações somáticas dos bebês. O modelo ocidental predominante sobre os bebês como pacotes biológicos pode mesmo ser aplicado universalmente? A visão dos Beng de que os bebês são recém-exilados do mundo espiritual de wrugbe - um modelo reproduzido em outros lugares - não sugere isso. Embora aparentemente frágeis e totalmente corporais, no modelo do ciclo de vida dos Beng, os bebês, na verdade, levam uma vida interior bastante rica. Nossas próprias afirmações - frequentemente inconscientes - sobre eles podem nos impedir de levar em conta essas ideologias alienígenas simplesmente porque não nos damos ao trabalho de questionar o mundo dos bebês.

Com efeito, se os ocidentais definem os processos racionais com base nas capacidades intelectuais - a habilidade de se comunicar por meio da fala, de construir redes sociais complexas e instituições, de organizar o mundo à sua volta, de planejar o futuro - o que sobra para os bebês - aparentemente especializados em processos mais primitivos como comer, 
dormir e fazer suas necessidades fisiológicas? Emily Martin (1999) assinalou o quanto os antropólogos privilegiam os sistemas racionais do pensamento sobre outros modos de experimentação da vida. O insight de Martin pode ser aplicado aos bebês. Independente da lógica que possam exibir, aparentam estar distantes dos padrões de racionalidade enunciados pelo pensamento ocidental formal construído ao longo de dois mil anos. Diante de um perfil intelectualmente problemático como esse, é compreensível que seja pequena qualquer inclinação para um estudo antropológico sério dessas criaturas (Peters, 1995).

\section{Em busca de uma Antropologia dos bebês (e de seus cuidadores)}

Bebês podem contribuir para a teoria social? Duas questões fundamentais poderiam ser produtivamente esclarecidas. A primeira diz respeito às relações entre estrutura e agência. Ironicamente, a tendência dos antropólogos de enfatizar a agência individual intensificou a incorporação, pela disciplina, de processos globais e históricos que, sob o ponto de vista analítico, podem facilmente dominar a agência individual. Temos visto uma avalanche de biografias de indivíduos e famílias (Briggs, 1998; Crapanzano, 1980; Ottenberg, 1996; Shostak, 1981; Werbner, 1991); relatos de vida social co-produzidos com informantes e intelectuais locais (Fischer \& Abedi, 1990; Gudeman \& Rivera, 1990; Whitten, Whitten, \& Chango, 1997); e tentativas teóricas, reflexivas ou programáticas de privilegiar as vozes dos nossos "informantes". Ao mesmo tempo, vemos análises da vida social baseadas nos efeitos de uma economia política globalizada e historicizada (Mintz, 1985; Roseberry, 1989). As direções divergentes dessas duas vertentes de estudo são um aspecto peculiar do cenário acadêmico das duas últimas décadas. Pode uma Antropologia dos bebês e da primeira infância evitar, por um lado, ir contra o Scylla da pura estrutura e, por outro, contra o Carybdis da pura agência?

Pode ser tentador em nível metodológico permitir que outras pessoas falem pelos bebês - permitir que uma Antropologia dos bebês se torne uma Antropologia da primeira infância vista pelos outros. Isso seria pressupor que os bebês estão completamente sujeitos às estruturas imaginadas por adultos, incapazes de afirmar qualquer subjetividade. Portanto, é justamente esse aspecto que precisamos evitar, já que uma Antropologia da primeira infância deve incluir não apenas a consideração da perspectiva dos outros sobre os bebês, mas, e tão importante quanto, uma Antropologia dos próprios bebês, baseada na premissa de que bebês podem eles próprios ser atores sociais (Morton, 1996), embora possam utilizar modos exóticos de comunicação. Já foram assinaladas anteriormente algumas mudanças metodológicas que uma Antropologia dos bebês bem desen- 
volvida necessitaria - incluindo sintonizar-se com formas somáticas de comunicação, com teorias locais sobre a comunicação dos bebês, assim como reconhecer que eles, assim como os adultos, são parte de um sistema cibernético no qual a identidade é definida como constitutiva da sociedade (Derné, 1992; Shweder \& Bourne, 1984).

Os bebês podem até mesmo nos oferecer um caminho intermediário entre estrutura e agência, precisamente na medida em que representam um caso extremo de teste. Na visão ocidental usual, bebês aparentam ser as criaturas mais dependentes e que apresentam menos iniciativa entre os humanos. Se, em outros lugares, são considerados responsáveis por suas ações, mesmo quando dependem de outras pessoas, esse seria um importante registro na questão da "agência". Já dei algumas indicações breves de um cenário como esse com base em meu trabalho de campo. Há sinais de outras sociedades em que o modelo da primeira infância dos Beng pode ser amplamente replicado (com variações locais) fora do mundo ocidental ${ }^{12}$. Alguns psicólogos do desenvolvimento e psicanalistas (Fogel, 1993; Stern, 1985) adotaram um modelo de comportamento de bebês mais interativo do que o que caracterizava o modelo dominante construído pelos primeiros pesquisadores, incorporando sua vida social e procurando reconhecer agência até mesmo nos primeiros dias de vida humana extrauterina. Se até mesmo os bebês modelam ativamente a vida das pessoas à sua volta, contribuindo para a constituição de seus mundos sociais, certamente deve haver uma lição para nós, como analistas que buscam a compreensão da vida social em geral. Investigar a maneira pela qual os bebês estão enredados na vida de seus parentes (Harkness \& Super, 1996; Le Vine, Miller, \& West, 1998) e em instituições mais amplas - tanto locais como globais também deve produzir um registro significativo na questão da "estrutura". Se prestarmos suficiente atenção às ideologias nativas relacionadas aos bebês, bem como a suas vidas cotidianas, eles poderiam nos guiar em direção à avaliação equilibrada de estrutura e de agência que tantos entre nós buscamos.

Uma avaliação intercultural adequada dos bebês pode também nos ajudar a superar nossas próprias convicções acerca da natureza da natureza e da natureza da cultura. Será que parte/a maior parte de/ tudo o que fazemos é forjado por estruturas biológicas imutáveis enraizadas em configurações genéticas que estamos apenas começando a mapear? Ou o comportamento humano é modelado por estruturas culturais flexíveis que são muito mais variáveis do que os modelos biológicos sugerem? Se a posição de compromisso frequentemente atraente - espere, são ambas! - prevalecer, cada uma delas é responsável por qual proporção, e como saberemos?

12 Na África Ocidental, esaa noção é bastante comum, por exemplo, entre os ljaw da Nigéria (Leis, 1982), os Bobo de Burkina Faso (Lemoal, 1981), os Yoruba e lgbo da Nigéria, e muitos outros povos. 
Os ocidentais tendem a supor que quanto mais jovem o indivíduo, mais dependente ele será da biologia e mais orientadas biologicamente serão as decisões dos cuidadores. No entanto, as normas de desenvolvimento foram construídas com base em crianças europeias e americanas de classe média, excluindo dos estudos a maioria das crianças do mundo, e tornando as chamadas "normas" vulneráveis a reformulações. Vimos que a idade com que os bebês aprendem a sentar independentemente é bem variável, mostrando que o tempo dessa aquisição motora é mais flexível do que até então se havia pensado. Por outro lado, a idade de quatro meses parece ser o menor tempo em que essa habilidade pode ser dominada. Se pudermos documentar o limite inferior e superior do espectro para a aquisição normal dessas primeiras atividades motoras, estaremos em uma posição melhor para entender o papel das práticas culturais na aceleração ou retardamento dessas aquisições.

O mesmo pode ser aplicado ao desenvolvimento social. Por exemplo, os psicólogos do desenvolvimento há muito tempo vêm propondo que a "ansiedade de separação" é um estágio universal dos bebês entre aproximadamente 7 e 12 meses. Os bebês Beng ocasionalmente apresentam esse comportamento nesse mesmo período em que os ocidentais o fazem. Mas longe de ser comum como ocorre com os bebês ocidentais, nos bebês Beng esse comportamento é raro e ativamente desaprovado - talvez porque famílias extensas permitam arranjos de cuidado muito flexíveis de um dia para outro para cada criança. Nesse caso, a interação entre o tempo biológico e as práticas culturais aparenta ser delicada, porém crítica.

Como sugerem esses exemplos, quando começarmos a estudar sistematicamente a vida de bebês e crianças pequenas em outros contextos culturais devemos conseguir transcender polêmicas e acessar de forma mais realística as contribuições relativas da cultura e da biologia para o desenvolvimento cognitivo, emocional, social e até mesmo motor nos primeiros estágios da vida pós-natal. Dessa forma, uma Antropologia dos bebês (e de seus cuidadores) poderia contribuir para os permanentes debates sociais e filosóficos sobre o papel da educação na formatação da vida humana. Como foi assinalado anteriormente (Lallemand \& Lemoal, 1981a), há bastante tempo as crianças figuram de forma ativa nesses debates, mas mais como marcos ideológicos do que etnográficos. Uma etnografia de bebês informada por trabalhos de campo poderia contribuir significativamente para essa discussão ainda em andamento. 


\title{
Where have all the babies gone? Towards an Anthropology of infants (and their caretakers)
}

\begin{abstract}
In much anthropological literature infants are frequently neglected as outside the scope of both the concept of culture and disciplinary methods. This article proposes six reasons for this exclusion of infants from anthropological discussion. These include the fieldworker's own memories and parental status, the problematic question of agency in infants and their presumed dependence on others, their routine attached to women, their seeming inability to communicate, their inconvenient propensity to leak from a variety of orifices, and their apparently low quotient of rationality. Yet investigation of how infants are conceived beyond the industrialized West can lead us to envision them far differently from how they are conceived in the West (including by anthropologists). Confronting such comparative data suggests the desirability of considering infants as both relevant and beneficial to the anthropological endeavor.
\end{abstract}

Keywords: Infants. Anthropology. Social theory. West Africa.

\section{Les bebés, ou sont-ils allés? Vers une Anthropologie de bebés (et de ceux qui les soignent)}

Résumé: Les bébés sont souvent négligés dans la littérature anthropologique, comme s'ils ne trouvaient pas de place dans le concept de culture ou dans les méthodes de cette discipline. Cet article présente six motifs de cette exclusion: les mémoires et le statut de l'anthropologue lui-même, en tant que père/ mère; la question problématique de l'agence du bébé et de sa prétendue dépendance à l'égard d'autres personnes; ses routines liées aux femmes; son apparente incapacité communicative; son inconvenante propension à verser travers des orifices divers; et son apparente rationalité faible. L'investigation des conceptions sur le bébé en dehors du monde occidental industrialisé peut nous conduire à une perception diverse de celle répandue dans l'Occident (y compris chez les anthropologues). La confrontation entre ces données comparatives suggère l'importance de regarder les bébés en tant que sujets importants et salutaires pour l'étude anthropologique.

Mots-clés: Enfance. Anthropologie.Theorie sociale. Afrique Occidentale. 


\section{Adónde se han ido los bebés? Buscando una Antropología de bebés ( $y$ de sus cuidadores)}

Resumen: En casi toda la literatura antropológica, los bebés son a menudo negligenciados, como si estuvieran fuera del ámbito del concepto de cultura, así como de los métodos de la disciplina. Este articulo propone seis razones para esa exclusión de los bebés del debate antropológico: las memorias y el status parental del propio antropólogo, la cuestión problemática de la agencia de los bebés y su supuesta dependencia de otras personas, sus rutinas vinculadas a las mujeres, su aparente incapacidad de comunicación, su inconveniente propensión a fluir por varios agujeros, y su aparente bajo grado de racionalidad. La investigación de como los bebés son concebidos fuera del mundo occidental industrializado puede llevarnos a percibir los bebés de una forma bastante distinta de la comprendida en el Occidente (incluso por antropólogos). El confronto de esos dados comparativos sugiere la importancia de considerarlos sujetos relevantes y benéficos para objetivos de la Antropología.

Palabras-clave: Lactante. Antropologia. Teoría social. África Occidental.

\section{Referências}

Appadurai, A. (1996). Modernity at large: Cultural dimensions of globalization. Minneapolis: University of Minnesota Press.

Arens, W., \& Karp, I. (Eds.). (1989). Creativity of power: Cosmology and action in African societies. Washington DC: Smithsonian Institution Press.

Ariès, P. (1962). Centuries of childhood: A social history of family life. London: Jonathan Cape.

Bakhtin, M. (1968). Rabelais and his world. Cambridge, MA: M.I.T. Press.

Barthes, R. (1972). Mythologies. New York: Noonday.

Bonnet, D. (1988). Corps biologique, corps social: Procréation et maladies de l'enfant en pays Mossi, Burkina Faso. Paris: Orstom.

Briggs, J. L. (1998). Inuit morality play: The emotional education of a three-year-old. New Haven, CT: Yale University Press.

Buckley, T., \& Gottlieb, A. (Eds.). (1988). Blood magic: The anthropology of menstruation. Berkeley: University of California Press.

Caplan, P. (Ed.). (1987). The cultural construction of sexuality. London: Tavistock.

Classen, C. (1992). The odor of the other: Olfactory symbolism and cultural categories. Ethos, 20(2), 133-166.

Cole, M. (1983). Society, mind, and development. In F. Kessel \& A. Siegel (Eds.), The child and other cultural inventions. New York: Praeger. 
Comaroff, J., \& Comaroff, J. (1991). Of revelation and revolution. Vol. 1: Christianity, colonialism, and consciousness in South Africa. Chicago: University of Chicago Press.

Comaroff, J., \& Comaroff, J. (1997). Of revelation and revolution. Vol. 2: The dialectics of modernity on a South African frontier. Chicago: University of Chicago Press.

Comaroff, J. (1987). Sui genderis: Feminism, kinship theory, and structural "domains". In J. Collier \& S. Yanagisako (Eds.), Gender and kinship: Toward a unified analysis (pp. 53-85). Stanford, CA: Stanford University Press.

Conklin, B. A., \&Morgan, L. M. M. (1996). Babies, bodies, and the production of personhood in North America and a Native Amazonian society. Ethos, 24(4), 657-694.

Counihan, C., \& Van Esterik, P. (Eds.). (1997). Food and culture: A reader. New York: Routledge.

Crapanzano, V. (1980). Tuhami: Portrait of a Moroccan. Berkeley: University of Chicago Press.

Crawford, C. J. (1994). Parenting practices in the Basque country: Implications of infant and childhood sleeping location for personality development. Ethos, 22(1), 42-82.

D'Alisera, J. (1998). Born in the USA: Naming ceremonies of infants among Sierra Leoneans in the American capital. Anthropology Today, 14(1), 16-18.

Davin, A. (1997). Imperialism and motherhood. In F. Cooper \& A. Stoler (Ed.), Tensions of empire: Colonial cultures in a bourgeois world (pp. 87-151). Berkeley: University of California Press.

Davis-Foyd, R. E., \& Sargent, C. F. (Eds.). (1997). Childbirth and authoritative knowledge: Cross-cultural perspectives. Berkeley: University of California Press.

Deloache, J. (1992). Perspectives on infant development. Lecture presented to Psych 318, September, University of Illinois at Urbana-Champaign.

Derné, S. (1992). Beyond institutional and impulsive conceptions of self: Family structure and the socially anchored real self. Ethos, 20(3), 259-288.

Dirks, N., Eley, G., \& Ortner, S. (Eds.). (1993). Culture, power, history. Princeton, NJ: Princeton University Press.

Douglas, M. (1966). Purity and danger. New York: Praeger.

Du, S. (2002). "Chopsticks always work in pairs": Gender unity and gender equality. New York: Columbia University Press.

Erny, P. (1988). Les premiers pas dans la vie de l'enfant d'Afrique noire: Naissance et première enfance. Paris: L'Harmattan.

Evans-Pritchard, E. E. (1940). The Nuer. Oxford: Oxford University Press.

Farnell, B. (1994). Ethno-graphics and the moving body. Man, 29(4), 929-974.

Ferreira, M. K. L. (1997). When $1+1=/ 2$ : Making mathematics in central Brazil. American Ethnologist, 24(1), 132-147.

Fischer, M., \& Abedi, M. (1990). Debating muslims: Cultural dialogues in postmodernity and traditions. Madison: University of Wisconsin Press. 
Fogel, A. (1993). Developing through relationships: Origins of communication, self, and culture. Chicago: University of Chicago Press.

Fortes, M. (1987). Religion, morality and the person: Essays on Tallensi religion. Cambridge: Cambridge University Press.

Franklin, S., \& Ragoné, H. (Eds.). (1998). Reproducing reproduction: Kinship, power, and technological innovation. Philadelphia: University of Pennsylvania Press.

Geertz, C. (1983). Local knowledge. New York: Basic Books.

Ginsburg, F., \& Rapp, R. (1991). The politics of reproduction. Annual Review of Anthropology, 20, 311-343.

Ginsburg, F., \& Rapp, R. (Eds.). (1995). Conceiving the new world order: The global politics of reproduction. Berkeley: University of California Press.

Goldberg, S. (1977). Ethics, politics and multicultural research. In P. H. Leiderman, S. R. Tulkin \& A. Rosenfeld (Eds.), Culture and Infancy (pp. 587-598). New York: Academic Press.

Goodwin, M. H. (1997). Children's linguistic and social worlds. Anthropology Newsletter, 38(4), 4-5.

Gottlieb, A. (1998). Do infants have religion? The spiritual lives of Beng babies (Côte d'Ivoire). American Anthropologist, 100(1), 122-135.

Gottlieb, A. (2000). Luring your child into this life: A beng path for infant care (Côte d'Ivoire). In J. S. DeLoache \& A. Gottlieb (Eds.), A world of babies: Imagined childcare guides for seven societies (pp. 55-89). New York: Cambridge University Press.

Gottlieb, A. (2004). The afterlife is where we come from: Infants and infant care in West Africa. Chicago: University of Chicago Press.

Gould, S. J. (January, 1996). Triumph of the root-heads: we undervalue an organism - and misread evolution - when we consider only adult anatomy. Natural History, 10-17.

Gross, D. R. (1984). Time allocation: A tool for the study of cultural behavior. Annual Review of Anthropology, 13, 519-558.

Gudeman, S., \& Rivera, A. (1990). Conversations in Colombia: The domestic economy in life and text. Cambridge: Cambridge University Press.

Gupta, A., \& Ferguson, J. (Eds.). (1997a). Anthropological locations: Boundaries and grounds of a field science. Berkeley: University of California Press.

Gupta, A., \& Ferguson, J. (Eds.). (1997b). Culture, power, place: Explorations in critical anthropology. Durham, NC: Duke University Press.

Hamilton, A. (1981). Nature and nurture: Aboriginal child-rearing in North-Central Arnhem Land. Canberra: Australian Institute of Aboriginal Studies.

Hanks, W. F. (1989). Texts and textuality. Annual Review of Anthropology, 18, 95-127.

Hannerz, U. L. F. (1996). Transnational connections: Culture, people, places. New York: Routledge.

Harkness, S., \& Super, C. (1983). The cultural construction of child development: a framework for the socialization of affect. Ethos, 11(4), 221-232. 
Harkness, S., \& Super, C. (Eds.). (1996). Parents' cultural belief systems: Their origins, expressions, and consequences. New York: Guilford Press.

Heath, S. B. (1983). Ways with words: Language, life and work in communities and classrooms. Cambridge: Cambridge University Press.

Héritier, F. (1994). Les deux sœurs et leur mére. Paris: Editions Odile Jacob.

Héritier, F. (1996). Masculin/féminin: La pensée de la differénce. Paris: Editions Odile Jacob.

Hewlett, B. (1991). Intimate fathers: The nature and context of Aka Pygmy paternal infant care. Ann Arbor: University of Michigan Press.

Hunt, N. R. (1997). "Le bébé en brousse": European women, African birth spacing, and colonial intervention in breast feeding in the Belgian Congo. In F. Cooper \& A. Stoler (Eds.), Tensions of empire: Colonial cultures in a bourgeois world (pp. 287321). Berkeley: University of California Press.

Itoua, F., Tettekpoe, D. A., Traoré, A., Békombo, M., Keita, T., M’Bay, M. et al. (1988). Mouvement International ATD-Quart Monde. In A. K. B. Tay \& G. C. Labarthe (Eds.), Famille, enfant et développement en Afrique. Paris: UNESCO.

James, A., \& Prout, A. (1990). Introduction. In A. James \& A. Prout, A. (Eds.), Constructing and reconstructing childhood: Contemporary issues in the sociological study of childhood (pp. 1-6). London: Falmer Press.

James, W. (1979). 'Kwanim Pa: The making of the Uduk people: An ethnographic study of survival in the Sudan-Ethiopian borderlands. Oxford: Clarendon Press/Oxford University Press.

Johnson, M. (2000). A passport to Alijana (the next world): Raising Mandinga children in Lisbon, Portugal. Paper presented at the conference on Mothering in the African Diaspora (Association for Research on Mothering), Toronto.

Jordan, B. (1993). Birth in four cultures: A cross-cultural investigation of childbirth in Yucatan, Holland, Sweden and the United States. Prospect Heights, IL: Waveland Press.

Jorgensen, D. (1983). Concepts of conception: Procreation ideologies in Papua New Guinea. Mankind (Special Issue), 14(1), 1-12.

Kilbride, J. E., \& Kilbride, P. L. (1975). Sitting and smiling behavior of Baganda infants: The influence of culturally constituted experience. Journal of Cross-Cultural Psychology, 6(1), 88-107.

Kilbride, P. L., \& Kilbride, J. E. (1990). Changing family life in East Africa: Women and children at risk. State College: Pennsylvania State University Press.

Lafontaine, J. S. (1985). Initiation: Ritual drama and secret knowledge across the world. Harmondsworth: Penguin.

Lallemand, S. (Ed.). (1991). Grossesse et petite enfance en Afrique de l'ouest et à Madagascar. Paris: L'Harmattan.

Lallemand, S., \& LeMoal, G. (1981a). Un petit sujet. Journal des Africanistes, 51(1-2), 5-21.

Lallemand, S., \& LeMoal, G. (Eds.). (1981b). Journal des Africanistes [Special issue on childhood], 51, 1-2. 
Lancy, D. (1996). Playing on the mother-ground: Cultural routines for children's development. New York: Guilford.

Langness, L. L. (1975). Margaret mead and the study of socialization. Ethos, 3(2), 97-112.

Le, H-N. (2000). Never leave your little one alone: Raising an Ifaluk child. In J. S. DeLoache \& A. Gottlieb (Eds.), A world of babies: Imagined childcare guides for seven societies (pp. 199-203). New York: Cambridge University Press.

Leis, N. (1982). The not-so-supernatural power of ljaw children. In S. Ottenberg (Ed.), African religious groups and beliefs: Papers in honor of William R. Bascom. Folklore Institute and Meerut (pp. 151-169). India: Archana Publications.

Lemoal, G. (1981). Les activités religieuses des jeunes enfants chez les Bobo. Journal des Africanistes, 5(1-2), 235-250.

Levine, R. A., Dixon, S., Levine, S., Richman, A., Leiderman, P. H., Keefer, C. H. et al. (Eds.), (1994). Child care and culture: Lessons from Africa. New York: Cambridge University Press.

Levine, R. A., Miller, P. M., \& West, M. M. (Eds.), (1988). Parental behavior in diverse societies. San Francisco: Jossey-Bass.

Lewis, M., \& Rosenblum, L. A. (Eds.). (1974). The effect of the infant on its caregiver. New York: John Wiley.

Lock, M. (1993). Cultivating the body: Anthropology and epistemologies of bodily practice and knowledge. Annual Review of Anthropology, 22, 133-155.

Lugo, A., \& Maurer, B. (Eds.). (2000). Gender matters: Rereading Michelle Z. Rosaldo. Ann Arbor, MI: University of Michigan Press.

Lutz, C. (1988). Unnatural emotions: Everyday sentiments on a Micronesian atoll and their challenge to Western theory. Chicago: University of Chicago Press.

Maher, V. (Ed.). (1992). The anthropology of breast-feeding: Natural law or social construct. Oxford: Berg.

Martin, E. (1999). Flexible survivors. Anthropology News, 40(6), 5-6.

Mead, M. (1963). Socialization and enculturation. Current Anthropology, 4(2), 184-207.

Mintz, S. (1985). Sweetness and power: The place of sugar in modern history. New York: Viking Press.

Morgan, L. M. (1996). Fetal relationality in feminist philosophy: An anthropological critique. Hypatia, 11(3), 47-70.

Morgan, L. M. (1997). Imagining the unborn in the Ecuadoran Andes. Feminist Studies, 23(2), 323-350.

Morton, H. (1996). Becoming Tongan: An ethnography of childhood. Honolulu: University of Hawaii Press.

Munroe, R. H., \& Munroe, R. L. (1980). Infant experience and childhood affect among the Logoli: A longitudinal study. Ethos, 8(4), 295-315.

Nieuwenhuys, O. (1996). The paradox of child labor and anthropology. Annual Review of Anthropology, 25, 237-251. 
Ottenberg, S. (1989). Boyhood rituals in an African society: An interpretation. Seattle: University of Washington Press.

Ottenberg, S. (1996). Seeing with music: The lives of three blind African musicians. Seattle: University of Washington Press.

Parin, P., Morgenthaler, F., \& Parin-Matthey, G. (1980). Fear thy neighbor as thyself: Psychoanalysis and society among the Anyi of west Africa. Chicago: University of Chicago Press.

Peters, E. (1995). The benefits of teaching a course on infancy. General Anthropology, 2(1), 14-15.

Piot, C. (1999). Remotely global: village modernity in West Africa. Chicago: University of Chicago Press.

Reese, D. (2000). A parenting manual, with words of advice for Puritan mothers. In J. DeLoache \& A. Gottlieb (Eds.), A world of babies: Imagined childcare guides for seven societies (pp. 29-32). New York: Cambridge University Press.

Riesman, P. (1992). First find yourself a good mother: The construction of self in two African American communities. New Brunswick, NJ: Rutgers University Press.

Roseberry, W. (1989). Anthropologies and histories: Essays in culture, history, and political economy. New Brunswick, NJ: Rutgers University Press.

Scheper-Hughes, N., \& Sargent, C. (Eds.). (1998). Small wars: The cultural politics of childhood. Berkeley: University of California Press.

Schieffelin, B. (1990). The give and take of everyday life: Language socialization of Kaluli children. Cambridge: Cambridge University Press.

Schieffelin, B., \& Ochs, E. (1986a). Language socialization. Annual Review of Anthropology, 15, 163-246.

Schieffelin, B., \& Ochs, E. (Eds.). (1986b). Language socialization across cultures. Cambridge: Cambridge University Press.

Seremetakis, C. N. (1991). The last word: Women, death, and divination in inner Mani. Chicago: University of Chicago Press.

Shostak, M. (1981). Nisa: The life and words of a !Kung woman. Cambridge MA: Harvard University Press.

Shweder, R. A., \& Bourne, E. J. (1984). Does the concept of the person vary crossculturally? In R. A. Shweder \& R. A. LeVine (Eds.), Culture theory (pp. 158-199). Cambridge: Cambridge University Press.

Small, M. (1998). Our babies, ourselves: How biology and culture shape the way we parent. New York: Doubleday.

Stack, C., \& Burton, L. M. (1994). Kinscripts: Reflections on family, generation, and culture. In E. N. Glenn, G. Chang \& L. R. Forcey (Eds.), Mothering: Ideology, experience, and agency (pp. 33-44). New York: Routledge.

Stephens, S. (Ed.). (1995). Children and the politics of culture. Princeton, NJ: Princeton University Press. 
Stern, D. N. (1985). The interpersonal world of the infant: A view from psychoanalysis and developmental psychology. New York: Basic Books.

Stoller, P. (1997). Sensuous scholarship. Philadelphia: University of Pennsylvania Press.

Strathern, A. J. (1997). Body thoughts. Ann Arbor: University of Michigan Press.

Super, C., \& Harkness, S. (1986). The developmental niche: A conceptualization at the interface of child and culture. International Journal of Behavior Development, 9, 1-25.

Super, C., \& Harkness, S. (Eds.). (1980). Anthropological perspectives on child development. San Francisco: Jossey-Bass.

Toren, C. (1988). Children's perceptions of gender and hierarchy in Fiji. In G. Jahoda \& I. Lewis (Eds.), Acquiring culture: Cross-cultural studies in child development (pp. 225-270). London: Croom Helm.

Toren, C. (1993). Making history: The significance of childhood for a comparative anthropology of mind. Man, 28, 461-478.

Wallace, E. R. (1983). Freud and anthropology: A history and reappraisal. New York: International Universities Press.

Weisner, T., \& Gallimore, R. (1977). My brother's keeper: Child and sibling caretaking. Current Anthropology, 18(2), 169-190.

Werbner, R. (1991). Tears of the dead: The social biography of an African family. Washington, DC: Smithsonian Institution Press.

Whiting, B. (Ed.). (1963). Six cultures: Studies of child rearing. New York: Wiley.

Whitten, N. E. Jr., Whitten, D. S., \& Chango, A. (1997). Return of the Yumbo: The indigenous caminata from Amazonia to Andean Quito. American Ethnologist, 24(2), 355-391.

Zaslavsky, C. (1973). Africa counts: Number and pattern in African culture. Westport, CT: Lawrence Hill.

Alma Gottlieb, University of Illinois at Urbana-Champaign, USA. Endereço para correspondência: Department of Anthropology, 109 Davenport Hall, 607 S. Mathews Ave, University of Illinois at Urbana-Champaign, Urbana, IL 61801 USA. Endereço eletrônico:ajgottli@illinois.edu

Recebido em: 19/02/2009

Aceito em: 18/05/2009 